THURSDAY, AUGUST 3, $187 \mathrm{I}$

\section{THE ADVANCEMENT OF SCIENCE IN SCHOOLS}

WHILE the leaders of Science are in session, and every topic of scientific interest can be brought before them with unusual force and most favourable publicity, we desire to urge the claims of one particular subject as lying at the foundation of all real scientific progress in this country. It is impossible that Science can take root amongst us, that it can inform the national mind or raise the national reputation, while it is excluded from the vast majority of our schools, and while the few schools which have ventured to introduce it are left to struggle unassisted against almost overwhelming difficulties. There are those who congratulate us on the advances made within the last two years, who point with pride to the Eton telescope and the Rugby laboratory, to the Botanical Garden of Clifton and the Scientific Society of Harrow. No doubt the evidence thus cited is most gratifying; no doubt the thanks of the community are due to the men whose individual wisdom and energy have made so admirable a beginning; but if their success is to produce in us only self-complacency, and to hide the enormous deficiencies which it ought to make more glaring and conspicuous, their efforts have been worse than vain.

Let 11.5 ask the following questions. Of our countless Secondary Schools how many teach or profess to teach Natural Science in any shape whatever? Are there twenty schools in England which teach it systematically on a scale at all extensive, with special master and necessary apparatus? Is there one which accords to it such a place in comparison with other subjects of school teaching as is due to its inherent educational value, its practical use in after life, and the extent to which it is attracting and unfolding the chief intellects of the day? Lastly, are the schools which teach it honestly working on a well-considered plan, agreed amongst themselves as to the economies of methods, subjects, tests; or are their systems contradictory and chaotic, are they ignorant of each others' experience, are their efforts tentative and independent, their results often nugatory, their progress necessarily slow?

There is but one answer to these questions. Science teaching in our schools is as yet potential merely. It rests with those whom we are addressing to make it actual. Observers most conversant with the difficulties which have hitherto kept Science out of schools or paralysed it when nominally admitted, feel most strongly that combined and intelligent action on its behalf, undertaken by men of commanding influence and reputation, is the one thing needful to ensure for it existence, vitality, and permanence. So long as the necessity of teaching it to boys was denied, the action of authority would have been premature. It was necessary that public opinion should be formed, and that experience and argument should work the slow process of conversion. But its claims are now, in theory, established. The most bigoted no longer venture to question its utility; the champions of the old exclusive and one-sided culture are silenced, if not convinced; the general public has pronounced warmly in its favour; the masters and managers of schools are prepared in almost all cases, freely or grudgingly, to admit it. And if this be so; if the principles of opposition are surrendered, and objection rests only upon details; if, further, the deterrent details thus interposing are notorious, and are of a kind which authority, or enlightenment, or guidance, placed in sufficient hands and wielded with sufficient energy, can obviate, surely we may call upon the men whom the suffrage of the scientific world has saluted as its leaders to originate such a plan and to carry out such measures as may supplement the victory of reason over prejudice by assisting willing votaries and kindling half-roused enthusiasm.

There are cases in which the support of external authority is needful for the introduction of Science into schools. Probably few of the readers of NATURE are aware how bitter an opposition is offered to Science teaching by the clergy in many parts of England. The schoolmaster, who, being himself a clergyman, ventures to insist on Science as a necessity in his school curriculum, finds him. self the object of a conspiracy as adroit as it is unscrupu. lous. No matter how able and energetic he may be; no matter how unmistakeably he may care for the moral and religious training of his boys; there is an accursed thing in the midst of him ; the word goes forth to ostracise him ; the dextrous calumny is dropped in fitting places, his neighbours send their sons elsewhere, and his schemes are broken up. This, which has happened more than once, must happen many times, unless such hapless pioneers of Science can be made to feel that they are backed by men of character, by men whose names are known, to whom they can appeal, who will interfere on their behalf with weight to convince or to overawe their persecutors.

In quite another way again authority is needed. Public competitive examinations, for the universities or elsewhere, must always exercise a paramount influence upon the schools, and must stamp in great measure the value of the subjects taught. It may well be doubted whether in the examinations for India and for Woolwich scientific excellence is appraised sufficiently high. It is quite certain that the influence of the universities both on the higher and lower schools is what it ought not to be in this respect. The local examinations, excellent in many points, vicious in some few, are most vicious in their operation upon Science. The unwise limitation of the subjects taken up, with the certainty that classical and mathematical papers gain many more marks than chemistry or mechanics, prevent the boys in a widely taught school from taking Science in at all, and help to deter masters from a subject which will not count in the examination. And unless they are closely watched, the "matriculation" or "leaving" examinations now contemplated both by Oxford and by Cambridge will be more disastrous still. Between the universities clinging to old subjects as desperately as they distrust the new, and the schoolmasters defeating by nearly ten to one the proposal to give boys the choice between a "linguistic" and a "scientific" matriculation, an obstacle more serious than any which now exists will be built up. in the path of Science teaching, if its natural supporters. stand aloof from the progress of a mischief which it now. lies within their power to avert. 
But if School Science lacks authority to help it, it lacks guidance and enlightenment still more. For it may be taken as an established fact that the head masters are, as a body, absolutely helpless. No one can doubt this who will peruse their published utterances on the subject at the Sherborne Meeting in December last. Nor need they be ashamed of the imputation. They owe their position in almost every case to their high classical or mathematical reputation. They are so large minded as to appreciate and to wish to foster in their school studies of whose details they know nothing, and should be allowed to feel that in opening their doors to Science they may fall back with confidence upon supreme and accredited advisers.
Think of the difficult points which, without previous experience of any kind, they are called upon to settle. The main subjects of teaching, their relative value, and the order in which they should be taught, the age at which scientific study should commence, the extent to which it may be optional or must be compulsory, the merits and demerits of bifurcation, the text-books to be used, the time to be allowed, the methods of teaching, the frequency of examinations, the mode of obtaining teachers, the necessary apparatus, the arrangement of museums, laboratories, botanic gardens, - on all these points and on more blank and total ignorance holds the minds of many masters, while others are puzzling them out with cruel

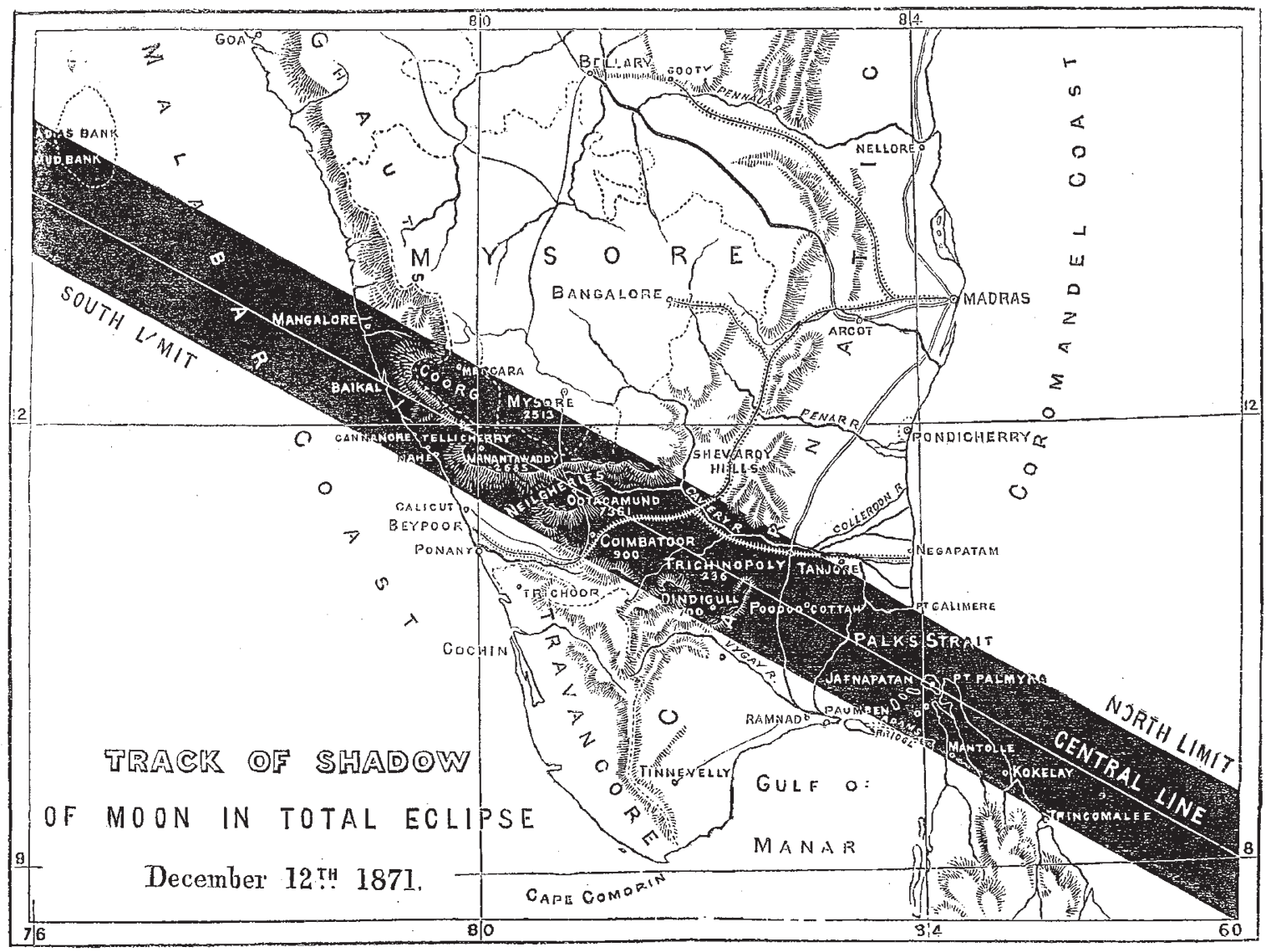

MAP OF THE PATH OF THE TOTAL SOLAR ECLIPSE IN DECEMBER NEXT

waste of force, destitute of traditions, ignorant of each others' experience, lacking central guidance.

For such guidance where are they to look, if not to the British Association? It includes men fitted for such a task beyond any others in the country, men individually of commanding reputation, representing severally the great towns, the Universities, the commercial centres. Is it too much to hope that a board of such men as these might assume, at the request and by the appointment of their brethren, the task of counsellers and supporters to the schools in the difficult task which lies before them? They might deliberate on the points which we have noticed, and draw up rules for a scientific course which all schools would adopt. They might send missionaries to schools newly entering upon their task, who should advise upon the many points no published rules could cover. They might suggest and accredit text-books, might bespeals and cheapen apparatus, might secure from Government facilities for obtaining specimens, for stocking gardens, for borrowing or renting instruments. Established more and more securely as the representatives and controllers of scientific education, they would see their power spread from the schools to the Universities, from the Universities throughout the country.

But we forbear. We have stated the difficulties which beset scientific education in our schools, we have hinted at means which may remove them. Our description is only too real, our project may be too chimerical. Be it 
so. The chimera of one age is often the truism of the next. Let us only call upon our friends at Edinburgh, before they separate for another year, to take this great subject into consideration, and to weigh its claims on their activity. Many a solitary teacher will be cheered, many a half-abandoned scheme will be preserved and furthered, if not by the certainty of their support, yet at any rate by the knowledge of their sympathy.

\section{THE APPROACHING TOTAL SOLAR ECLIPSE}

W $\mathrm{E}$. regret that we have, as yet, nothing very definite to announce in addition to what has been already stated with reference to the observations of the Total Solar Eclipse of the r2th of December next. We believe that an appeal is about to be made to Government, and if this be so, we may trust that anything that may be asked in the interests of Science will readily be granted by the Government. It is unfortunate that the Astronomer Royal's official position prevents his joining in the request, for his experience in connection with the large expenditure (10,000l. has already been voted) incurred by him for the approzching observation of the Transit of Venus, would be valuable in showing the necessity for the sum now required. This amounts only to a few hundreds in excess of the sum saved by the rigid economy practised by the Committee appointed to organise the arrangements connected with the late expedition.

We trust that the proposed arrangements will be brought before the British Association, in order that the influence of that important body may be made to bear upon this matter. We have recently shown the important results obtained by the late observations. It seems clear that the weather prospects for the approaching event are good, while recent calculations made by $\mathrm{Mr}$. Hind show that the totality in Ceylon is much longer than had been at first imagined, amounting to as much as $2^{\mathrm{m}}{ }_{11} \mathrm{I}^{\mathrm{s}}$ for Trincomalee, and therefore longer in the central line a few miles to the north. The accompanying map shows approximately the shadow path over India, and gives us good ground for congratulating ourselves that there are already in that country such observers as Tennant, Pogson, Herschel, Hennessy, and others, ready to occupy the best stations. The appeal made to Government includes funds for an expedition to Ceylon, under the charge of $\mathrm{Mr}$. Lockyer, who has been requested by the Royal Astronomical Society to undertake spectroscopic observations there, while M. Janssen will probably take up his station in Java. We have already stated that a strong party from Melbourne and Sydney will observe in the north of Australia. All then is in order, provided our scientific leaders will put their shoulders to the wheel.

\section{NOTES}

THE American Association for the Advancement of Science, which meets a fortnight later than our own at Indianapolis, is modelled in most respects after the pattern of the parent institution, but presents some features which the managers of our own Association may do well to take into consideration. The arranyements with regard to the opening address, sectional proceedings, \&c., are very similar, the following being the officers for the Indianopolis meeting:--President, Prof. Asa Gray, of
Cambridge ; Vice-president, Prof, George F. Barker, of New Haven; Permanent Secretary, Prof. Joseph Lovering, of Cambridge; General Secretary, Mr. F. W. Putman, of Salem; Treasurer, Mr. Wm. S. Vaux, of Philadelphia. Special convenience will be provided for microscopists in relation to the exhibition and care of any instruments or apparatus, a suite of rooms having been secured in the State House for their special use. It will be remembered that the same thing was attempted at the Liverpool meeting, but in rather a private and unacknowledged manner. Excursions are arranged to Terre Haute, a distance of seventy-three miles, including a visit to the celebrated block coal field and blast furnaces of Clay county, and to New Albany on the Ohio river, where there are a number of interesting manufactories, among them the only finishing plateglass works in the United States. Special arrangements have been made as to terms for the accommodation of the members of the Association at hotels and boarding-houses, and it is expected that all the railroads will carry the visitors at half fares.

Although the Report of the Science and Art Department in the year 1870 is not yet published, we believe that the following chief results, taken from the Times, may be relied upon as accurate. The numbers who during 1870 have attended the schools, museums, and other institutions receiving Parliamentary aid, con. siderably exceed those of 1869 . There is a very large increase in the number of persons receiving instruction in science applicable to industry, which has risen from 24,865 in 1869 to 34,283 in 1870 , or upwards of 37 per cent. At the Royal School of Mines there were I' regular and 124 occasional students, at the Royal College of Chemistry I2I students, at the Royal School of Naval Architecture there were 40, and at the Metallurgical Laboratory 24. The evening lectures at the Royal School of Mines were attended by 2,574 artisans, school teachers, and others; and 243 science teachers attended the special courses of lectures provided for their instruction. At the Royal College of Science, Ireland, there were 17 associate or regular students and 2 I occasional students. The various courses of lectures delivered in connection with the department in Dublin were attended by I, 152 persons, and at the Evening Popular Lectures, which were given in the Edinburgh Museum of Science and Art during the session 1869.70 , there was an attendance of $I, 195$. The total number of persons who received direct instruction as studen's or by means of lectures in connection with the Science and Art Department in 1870 was upwards of 254,000 . showing an actual increase as compared with the number in the previous year of 67,000 , or nearly 36 per cent., and an increase in the rate of progress of 8 per cent; ; the numbers in 1869 having been nearly 28 per cent. higher than in 1868 . The museums and collections under the superintendence of the department in London, Dublin, and Edinburgh, have been visited during the past year by I, 847,929 persons, showing an increase of 49,087 on the number in 1869. As we have said before, it is impossible to over-estimate the importance of the work which is being done.

THE correspondence between the Royal Commission on Scientific Instruction and the Advancement of Science and the Science and Art Department on the subject of the transfer of the School of Mines to South Kensington, has been presented to Parliament.

THE assertion made by a contemporary relative to the endowment at University College of a De Morgan professorship of mathematics, has given rise to the statement by Prof. T. Hewitt Key, to the effect that he now withdraws the proposal, not merely because it is said by the family to be at variance with the expressed wishes of the deceased, but more because it has been hinted that he has been unworthily " using Prof. de Mor. gan's name against such expressed wishes for the emolument of the college." The endowment of a mathematical chair still remains as an object to which his best energies will be applied. 